\title{
A Versatile Control Scheme for UPQC for Power Quality Improvement using fuzzy controller
}

\author{
B.Suresh Kumar \\ Department of Electrical \& Electronics Engineering, CBIT, HYDERABAD, India
}

\begin{abstract}
The proliferation of power electronics based equipment has produced a significant impact on the quality of electric power supply. Conventional power quality mitigation equipment is proving to be inadequate for an increasing number of applications, and this fact has attracted the attention of power engineers to develop dynamic and adjustable solutions to power quality problems. This has led to development of Custom Power Devices (CPD). One modern and very promising CPD that deals with both load current and supply voltage imperfections is the Unified Power Quality Conditioner (UPQC).

This paper investigated the development of UPQC control schemes and algorithms for power quality improvement and implementation of a versatile control strategy to enhance the performance of UPQC. The proposed control scheme gives better steady-state and dynamic response. The validity of the proposed control method is verified by means of MATLAB/SIMULINK
\end{abstract}

Index Terms: - CPD, UPQC, POWER QUALITY.

\section{INTRODUCTION}

Reliability of supply and power quality (PQ) are two most important facets of any power delivery system today [1]. Not so long ago, the main concern of consumers of electricity was the continuity of supply. However nowadays, consumers want not only continuity of supply, but the quality of power is very important to them too. The power quality problems in distribution power systems are not new, but customer awareness of these problems has recently increased. The power quality at the point of common coupling (PCC) with the utility grid is governed by the various standards and the IEEE-519 standard is widely accepted.

Utilities and researchers all over the world have for decades worked on the improvement of power quality. There are sets of conventional solutions to the power quality problems, which have existed for a long time. However these conventional solutions use passive elements and do not always respond correctly as the nature of the power system conditions change. The increased power capabilities, ease of control, and reduced costs of modern semiconductor devices have made power electronic converters affordable in a large number of applications. New flexible solutions to many power quality problems have become possible with the aid of these power electronic converters.

Nowadays equipment made with semiconductor devices appears to be as sensitive and polluting as ever [2]. Non-linear devices, such as power electronics converters, increase overall reactive power demanded by the equivalent load, and injects harmonic currents into the distribution grid. It is well known that the reactive power demand causes a drop in the feeder voltage and increases the losses. The presence of harmonic currents can cause additional losses and voltage waveform distortions, and so cause poor power quality. Also, the number of sensitive loads that require ideal sinusoidal supply voltages for their proper operation has increased. The increasing use of electronic equipment sensitive to power variations drives the interest in power conditioning technologies. So, in order to keep the power quality within limits proposed by standards, it is necessary to include some sort of compensation.

The power electronic based power conditioning devices can be effectively utilized to improve the quality of power supplied to customers [3]. One modern solution that deals with both load current and supply voltage imperfections is the Unified Power Quality Conditioner (UPQC) [9], which was first presented in 1995 by Hirofumi Akagi. Such a solution can compensate for different power quality phenomena, such as: sags, swells, voltage imbalance, flicker, harmonics and reactive currents.

UPQC is a combination of series and shunt active filters connected in cascade via a common dc link capacitor. The series active filter inserts a voltage, which is added at the point of the common coupling (PCC) such that the loadend voltage remains unaffected by any voltage disturbance. The main objectives of the shunt active filter are: to compensate for the load reactive power demand and unbalance, to eliminate the harmonics from the supply current, and to regulate the common dc link voltage.

The paper is organized as follows. The structure of the UPQC is presented in Section II. Then, in Section III, the control principles are described in detail. The simulation model is presented in Section IV. 
Simulation results in this section demonstrate the efficacy and versatility of the proposed design technique. Finally, Section V gives the conclusion.

\section{STRUCTURE OF UPQC}

The UPQC is a custom power device that integrates the series and shunt active filters, connected back-to-back on the dc side and sharing a common DC capacitor, as shown in Fig.2. It employs two voltage source inverters (VSIs) that are connected to a common DC energy storage capacitor. One of these two VSIs is connected in series with the feeder and the other is connected in parallel to the same feeder.

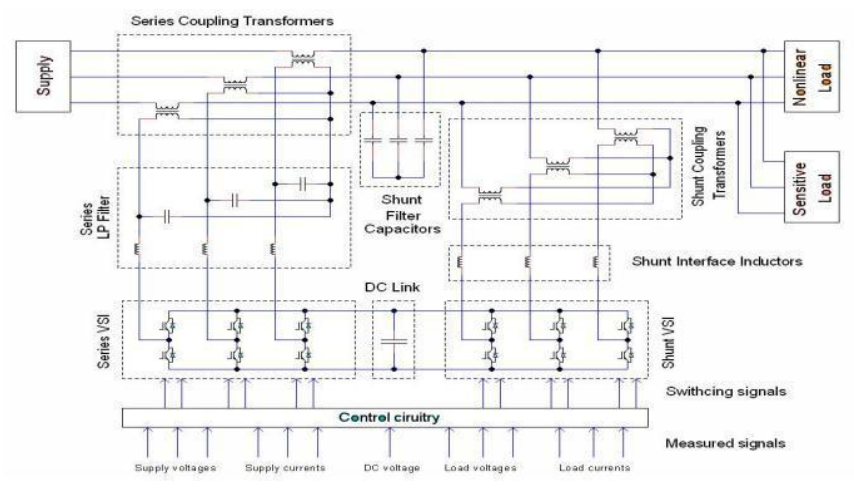

Fig.2. Power circuit diagram of a three-phase UPQC

\section{CONTROL STRATEGY}

The effectiveness of an active power filter depends basically on the design characteristics of the current controller, the method implemented to generate the reference template and the modulation technique used. The control scheme of a shunt active power filter must calculate the current reference waveform for each phase of the inverter, maintain the dc voltage constant, and generate the inverter gating signals. Also the compensation effectiveness of an active power filter depends on its ability to follow the reference signal calculated to compensate the distorted load current with a minimum error and time delay.

\section{A. Control of the shunt active filter}

The hysteresis control appears to be the most preferable for shunt active filter applications. Therefore, in the UPQC simulation model (presented in Fig.4),a hysteresis controller has been used.. The hysteresis control method has simpler implementation, enhanced system stability, increased reliability and response speed [13].

The shunt active filter is responsible for power factor correction and compensation of load current harmonics and unbalances. Also, it maintains constant average voltage across the DC storage capacitor. The shunt part of the UPQC consists of a VSI (voltage source inverter) connected to the common DC storage capacitor on the dc side and on the ac side it is connected in parallel with the load through the shunt interface inductor and shunt coupling transformer. The shunt interface inductor, together with the shunt filter capacitor are used to filter out the switching frequency harmonics produced by the shunt VSI. The shunt coupling transformer is used for matching the network and VSI voltages.

The series active filter compensation goals are achieved by injecting voltages in series with the supply voltages such that the load voltages are balanced and undistorted, and their magnitudes are maintained at the desired level. This voltage injection is provided by the dc storage capacitor and the series VSI. Based on measured supply and/or load voltages the control scheme generates the appropriate switching signals for the series VSI switches. The output voltages of the series VSI do not have the shape of the desired signals, but contain switching harmonics, which are filtered out by the series low pass filter. The amplitude, phase shift, frequency and harmonic content of injected voltages are controllable.

The design of UPQC power circuit includes the selection of the following three main parameters: shunt interface inductors; dc link reference voltage; dc link capacitor 


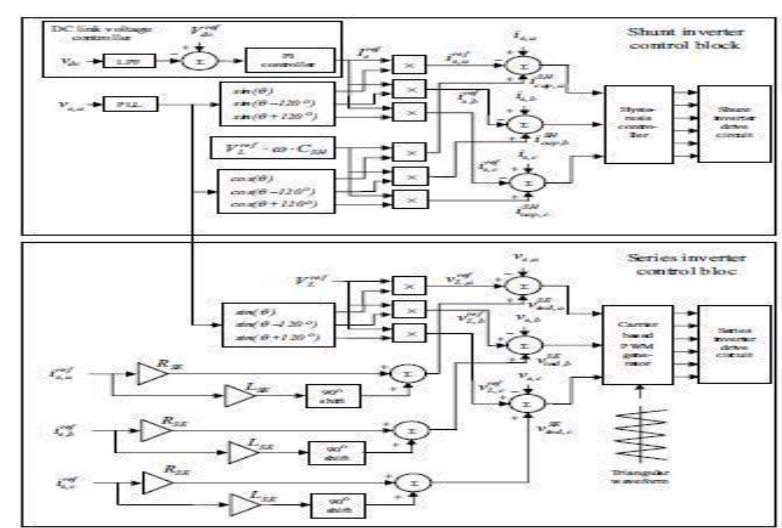

Fig.3 Block diagram of the UPQC overall control scheme

\section{B. Control of the series active filter}

The series component of UPQC is controlled to inject the appropriate voltage between the point of common coupling (PCC) and load, such that the load voltages become balanced, distortion free and have the desired magnitude. Two UPQC terms are defined in depending on the angle of the injected voltage: UPQC-Q and UPQC-P. In the first case (UPQC-Q) the injected voltage is maintained 90 degrees in advance with respect to the supply current, so that the series compensator consumes no active power in steady state. In second case (UPQC-P) the injected voltage is in phase with both the supply voltage and current, so that the series compensator consumes only the active power, which is delivered by the shunt compensator through the dc link. In the case of quadrature voltage injection (UPQC-Q) the series compensator requires

additional capacity, while the shunt compensator VA rating is reduced as the active power consumption of the series compensator is minimised and it also compensates for a part of the load reactive power demand.

In UPQC-P case the series compensator does not compensate for any part of the reactive power demand of the load, and it has to be entirely compensated by the shunt compensator. Also the shunt compensator must provide the active power injected by the series compensator. Thus, in this case the VA rating of the shunt compensator increases, but that of the series compensator decreases.

In the case when the UPQC-P control strategy is applied, the injected voltage is in phase with the supply voltage; hence the load voltage is in phase with the supply voltage and there is no need for calculating the angle of the reference load voltage. Thus, the reference load voltage is determined by multiplying the reference magnitude (which is constant) with the sinusoidal template phase-locked to the supply voltage. Then, the reference series filter voltage is obtained.

Comparing the techniques for calculating the reference voltage of the series compensator, presented above, it can be concluded that the UPQC-P algorithm has the simplest implementation (it involves very little computation). In the UPQC-P case the voltage rating of the series compensator is considerably reduced. Also, the UPQC-Q compensation technique does not work in the case when the load is purely resistive. Therefore, the UPQC-P control strategy has been used in the UPQC simulation model. PI controller has been used for dc link voltage control in the UPQC simulation model.

\section{SIMULATIONS AND RESULTS}

A UPQC simulation model( Fig.4) has been created in MATLAB/Simulink so as to investigate UPQC circuit waveforms, the dynamic and steady-state performance, and voltage and current ratings.

The following typical case studies have been simulated and the results are presented .

1. Short duration three phase fault conditions.

2. Long duration three phase fault conditions.

3. Dynamic load and three phase fault conditions.

4. Harmonic compensation

5. DC link voltage regulation for the above conditions is also verified. 


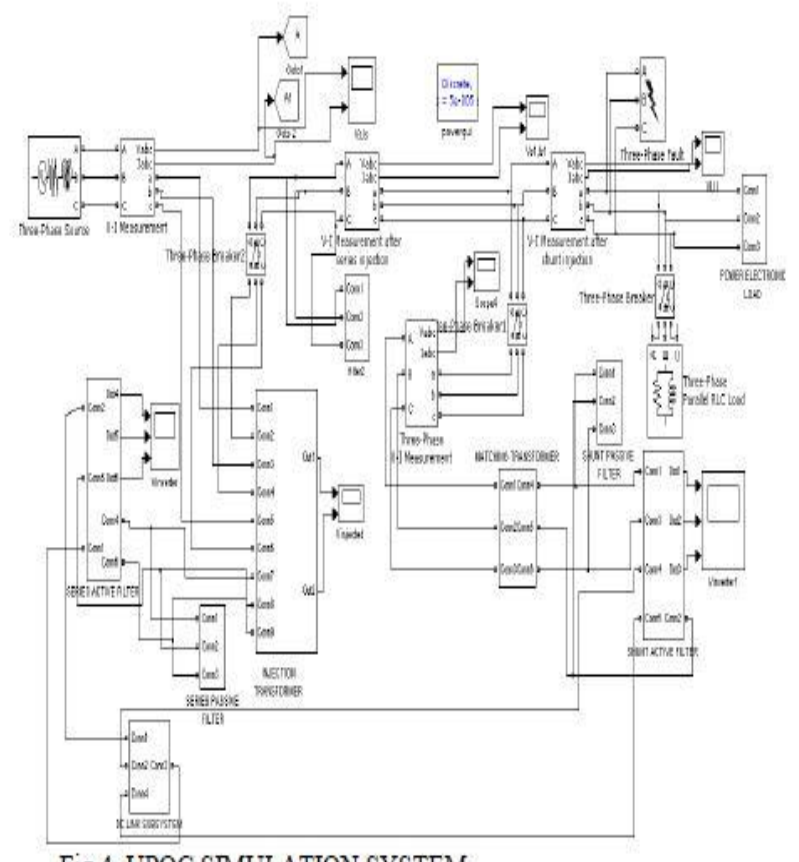

Fig 4. UPQC SIMULATION SYSTEM
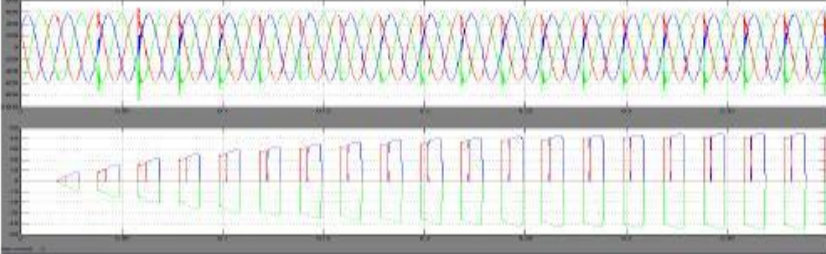

Fig 5. Steady state source voltage and load current waveforms (without UPQC) THD of source voltage:25.9\% ;THD of load current:63\%

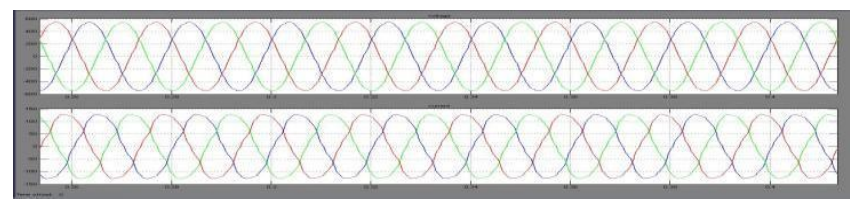

Fig 6.Steady state source voltage and load current waveforms (with UPQC) THD of source voltage: $0.98 \%$;THD of load current: 1.03

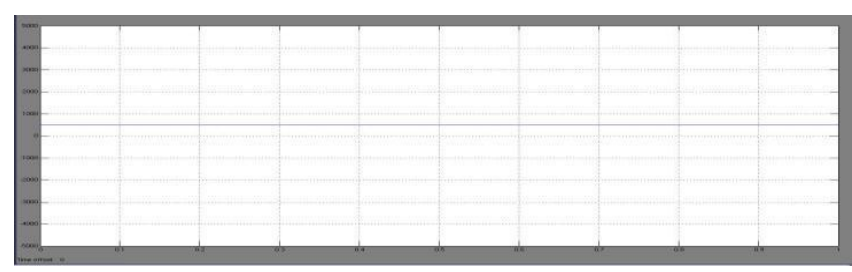

Fig 7.Steady State DC link voltage(500V)

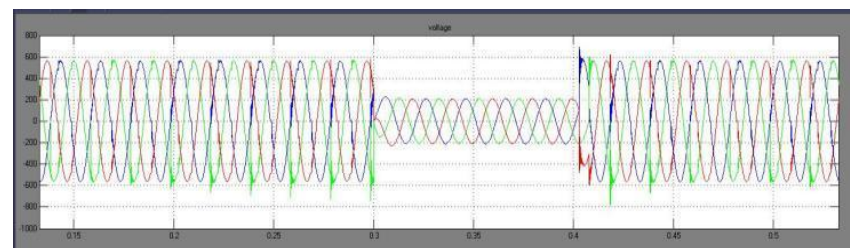

Fig 8.Source voltage when a three phase fault is introduced from 0.3 to 0.4 seconds. (without UPQC) 
(THD:27\%)

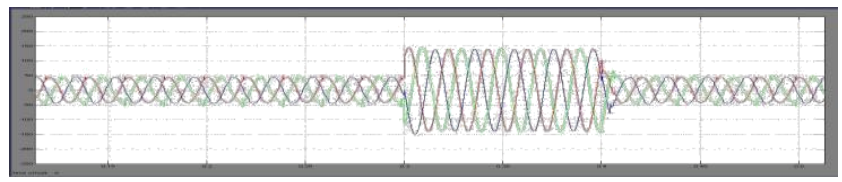

Fig 9.Compensating voltage injected by series active filter .

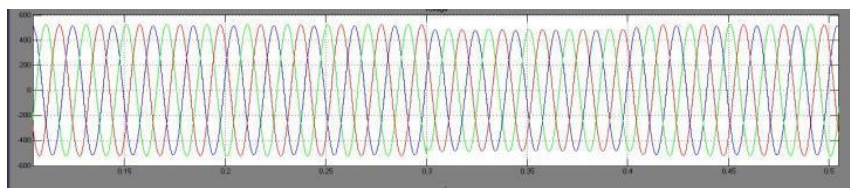

Fig 10.Source voltage when a three phase fault is introduced from 0.3 to 0.4 seconds. (with UPQC) (THD: $0.50 \%)$

Figure 8-10 shows the simulation results when a three phase fault is introduced, the series active filter(DVR) injects the compensating voltage so that the source voltage is maintained constant. This shows that voltage imperfections are compensated by the series part of UPQC.

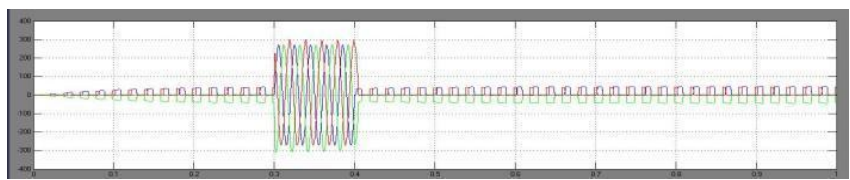

Fig 11.Load current when a three phase fault is introduced from 0.3 to 0.4 seconds. (without UPQC)

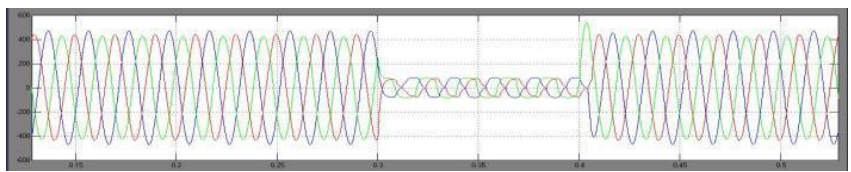

Fig 12. Compensating current injected by shunt active filter

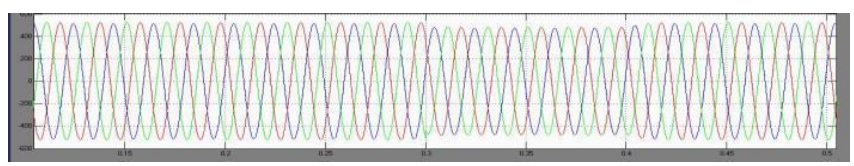

Fig 13. Load current when a three phase fault is introduced from 0.3 to 0.4 seconds. (with UPQC)

Figure 11-13 shows that when there is current distortions, the shunt part (D-STATCOM) maintains balance and filters out harmonics .

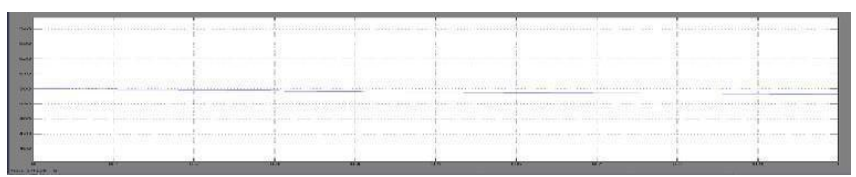

Fig 14. DC link voltage when a three phase fault is introduced from 0.3 to 0.4 seconds. (with UPQC)

The DC link voltage is maintained constant by the shunt compensator.

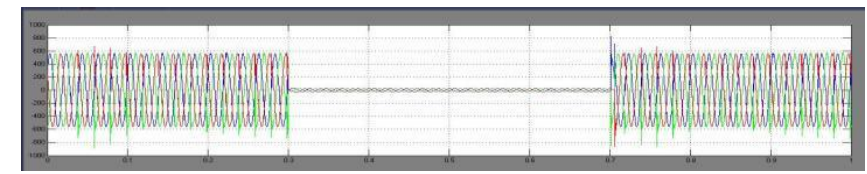

Fig 15. Source voltage when a three phase fault is introduced from 0.3 to 0.7 seconds. (without UPQC)

Figure 15 shows the case when the fault duration is increased to $0.4 \mathrm{~s}$. 


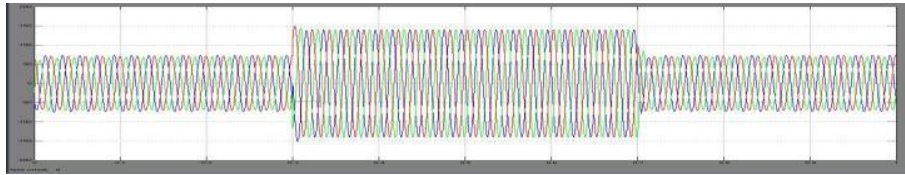

Fig 16. Compensating voltage injected by series active filter

Figure 16 shows that DVR injects the required voltage during fault .

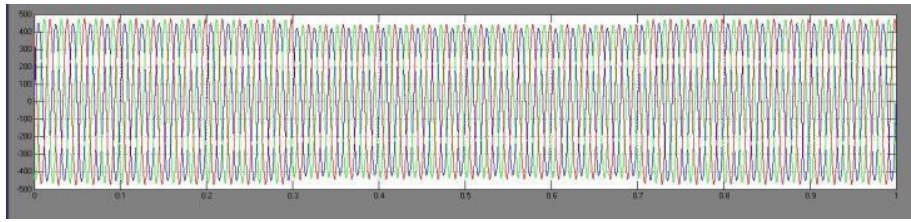

Fig 17.Source voltage when a three phase fault is introduced from 0.3 to 0.7 seconds. (with UPQC)

Figure 17 validates that UPQC can mitigate long duration sags effectively.

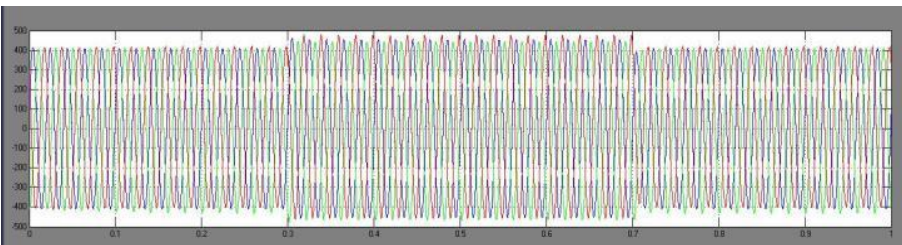

Fig 18. Load current when a three phase fault is introduced from 0.3 to 0.7 seconds. (without UPQC)

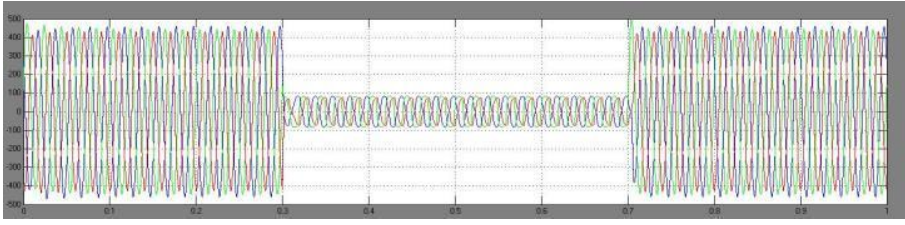

Fig 19.Compensating current injected by shunt active filter .

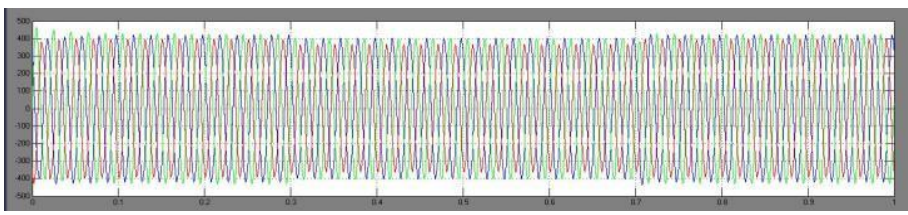

Fig 20.Load current when a three phase fault is introduced from 0.3 to 0.7 seconds. (with UPQC)

Figure 18-20 shows that long duration current faults are mitigated by D-STATCOM.

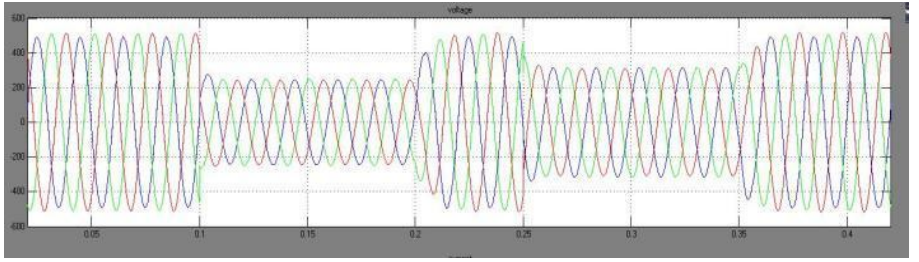

Fig 21.Source voltage when a three phase fault is introduced from 0.1 to 0.2 seconds and an RLC load from 0.25 to 0.35 seconds. (without UPQC)

Figure 21 shows the transient case where both fault and dynamic load is introduced at different time instants . 


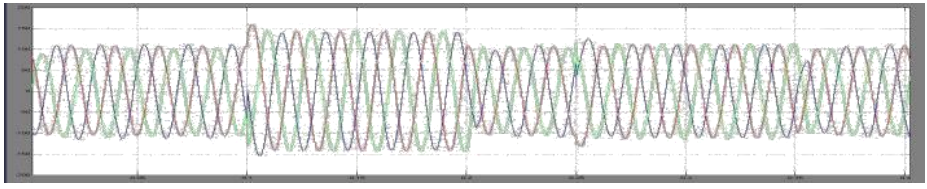

Fig 22.Compensating voltage injected by series active filter

DVR compensates for the sag by injecting more voltage when sag occurs in the system.

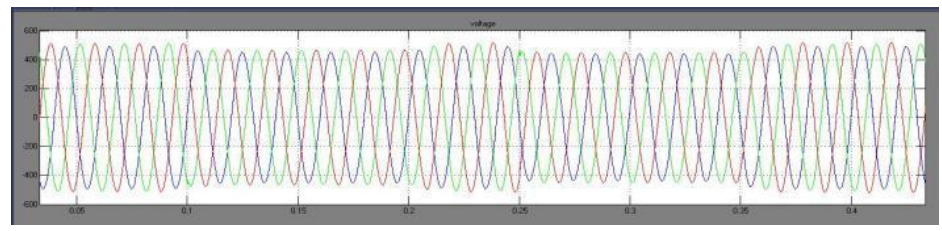

Fig 23.Source voltage when a three phase fault is introduced from 0.1 to 0.2 seconds and an RLC load from 0.25 to 0.35 seconds. (with UPQC)

Thus the source voltage is regulated and maintained constant by the UPQC.

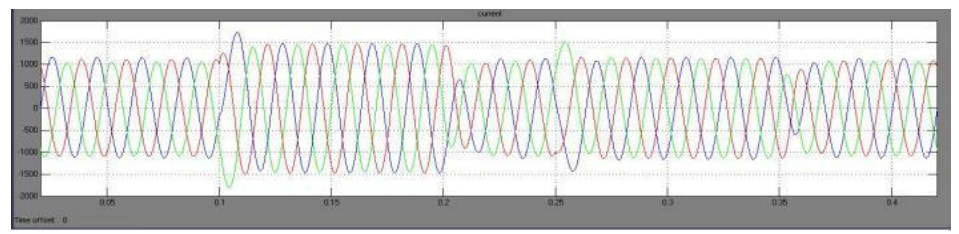

maintained constant by UPQC.

Simulation results show that UPQC mitigates deeper sags, harmonic compensation is better, does better load regulation and balancing for dynamic loads and can tolerate long duration fault conditions effectively. Thus it gives enhanced performance when compared to DSTATCOM and DVR. Results show that it gives good steady state and transient performance. The proposed control scheme is feasible and simple to implement although further work is needed to optimize the parameters of the UPQC.

\section{Results Using Fuzzy Controller}

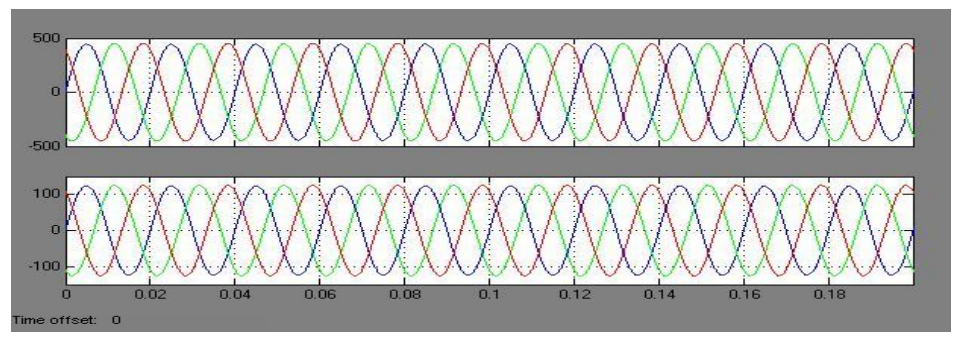

Fig 24..Load current when a three phase fault is introduced from 0.1 to 0.2 seconds and an RLC load from 0.25 to 0.35 seconds. (without UPQC)

Figure 24 shows the case when load current is distorted and unbalanced.

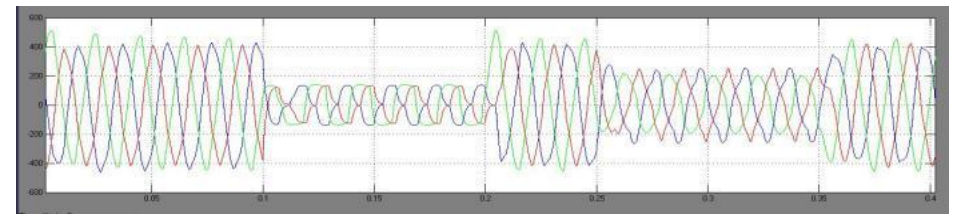

Fig 25 .Compensating current injected by shunt active filter 


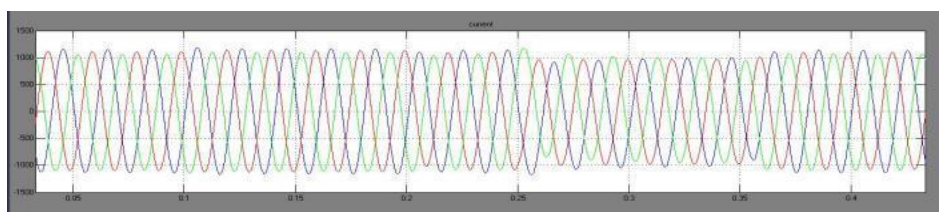

Fig 26.Load current when a three phase fault is introduced from 0.1 to 0.2 seconds and an RLC load from 0.25 to 0.35 seconds. (with UPQC)

D-STATCOM injects current waveforms of opposite polarity and mitigates the swell in current.

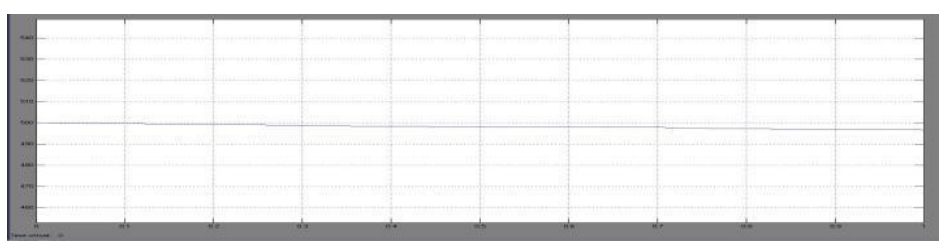

Fig 27. DC link voltage when a three phase fault is introduced from 0.1 to 0.2 seconds and an RLC load from 0.25 to 0.35 seconds. (with UPQC).

DC link voltage dips slightly during fault condition but is

Fig 28 Steady state Source Voltage and Load Current Waveforms (with UPQC) by using Fuzzy Controller

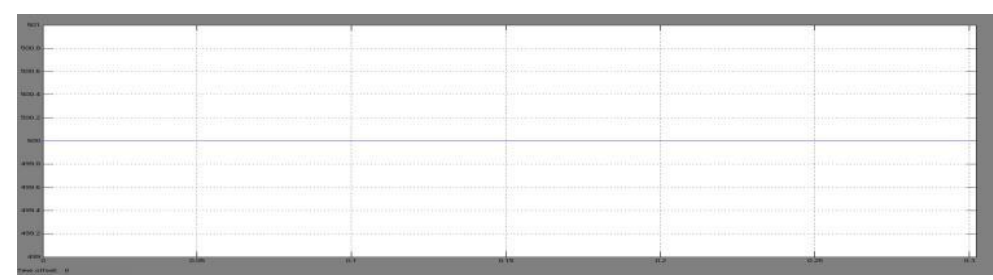

Fig 29 Steady state dc link Voltage by using Fuzzy Controller

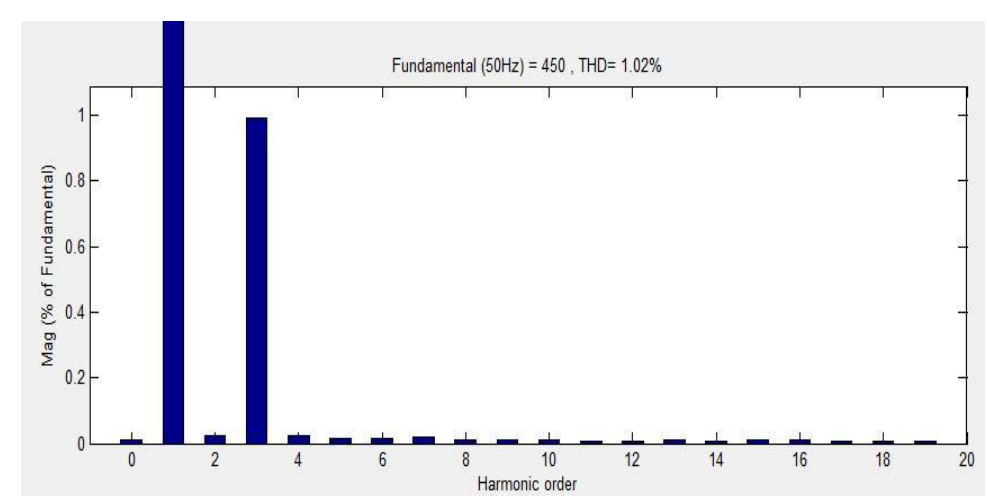

Fig 30 THD of Source Voltage in Steady State

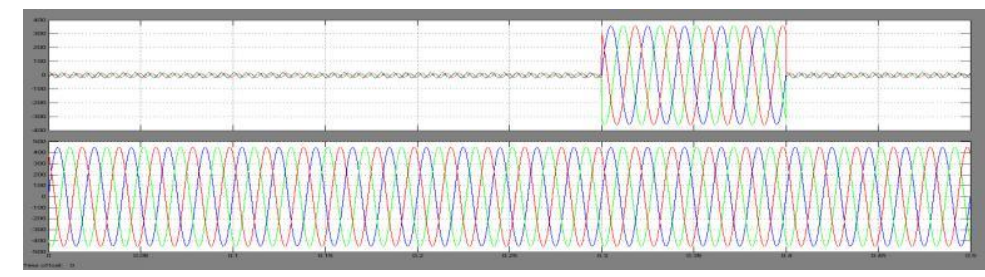

Fig 31 Voltage injected by Series active Filter(Vse) and Source Voltage(Vs) when 3 - phase fault is introduced(with UPQC) by using fuzzy controller 
Fig. 32 current injected by shunt active filter (Ish) and Load current (Il) when 3-phase fault is introduced (with UPQC) by using fuzzy controller

Fig.37DC link voltage when both 3-phase fault and RLC load are applied
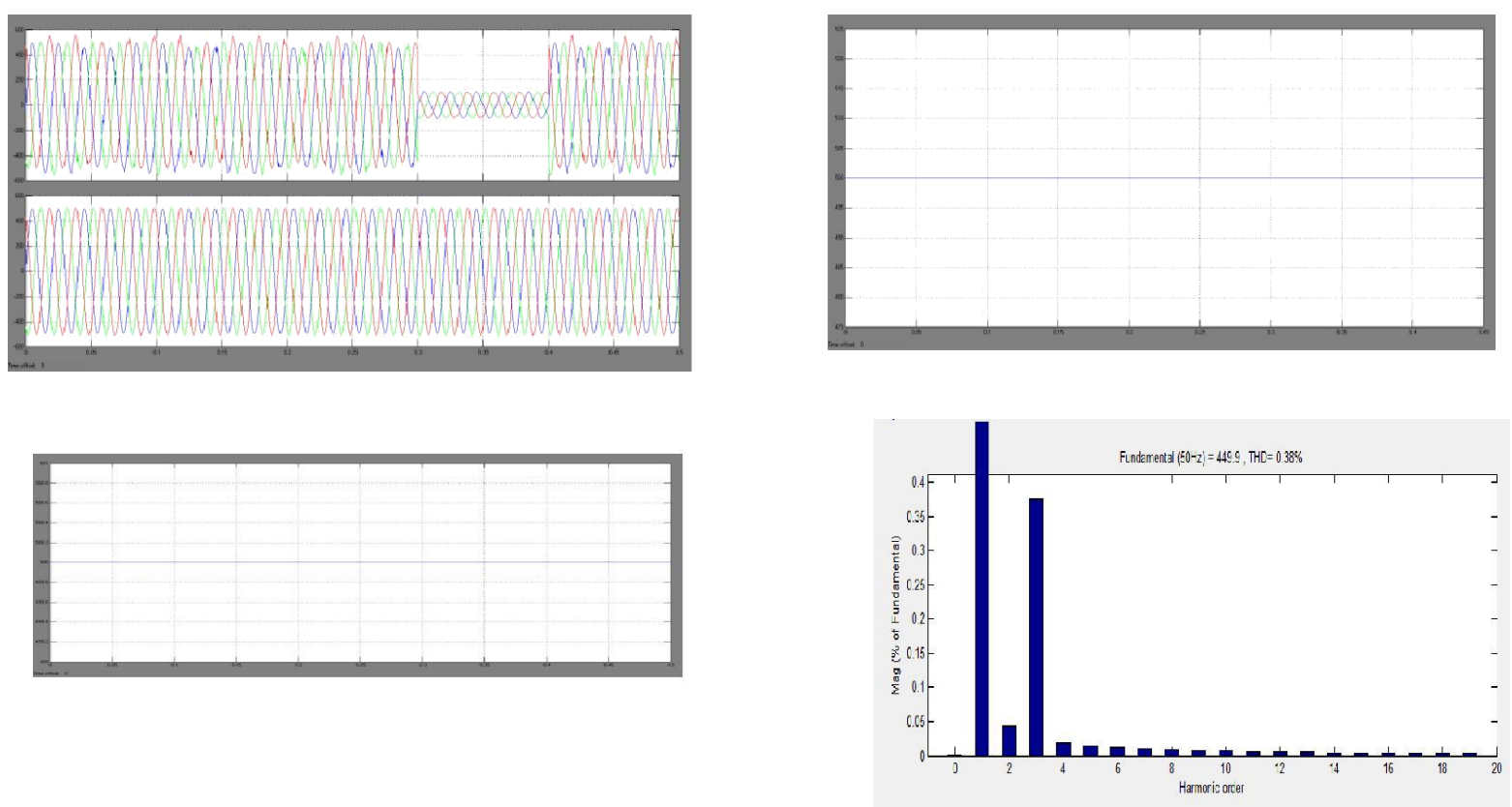

Fig .38 THD of source voltage when both 3-phase fault and RLC load are applied

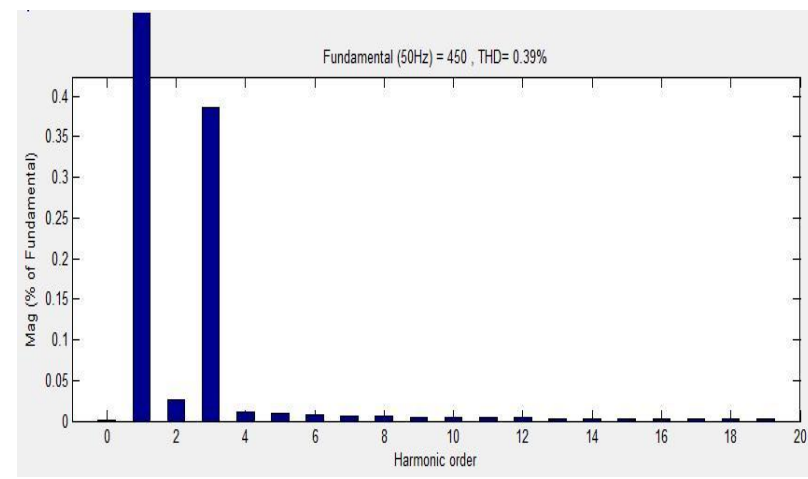

Fig.33 DC link Voltage When 3-phase is introduced

Fig .34 THD of source voltage when 3-phase fault is applied by using fuzzy controller

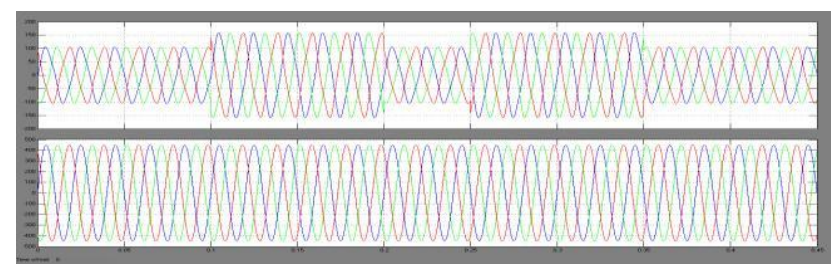

Fig.35 Compensating voltage injected by series active filter(Vse) and source voltage (Vs) when 3-phase fault is introduced from 0.1 to 0.2 seconds and an RLC load from 0.25 to 0.35 seconds (with UPQC) by fuzzy controller 


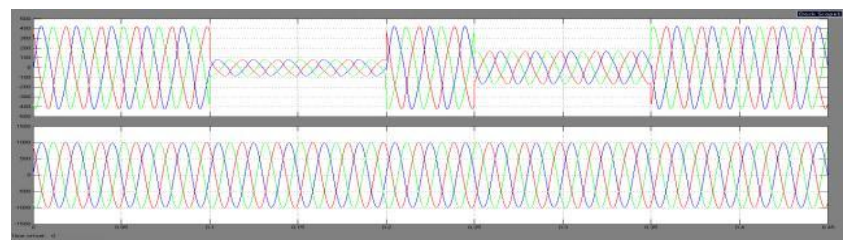

Fig.36 Compensating current injected by shunt active filter (Ish) and load current (II)when 3-phase fault is introduced from 0.1 to 0.2 seconds and an RLC load from 0.25 to 0.35 seconds (with UPQC) by fuzzy controller

\section{CONCLUSIONS}

The main objective of this work is to develop a versatile UPQC control scheme for power quality improvement and investigated the development of UPQC control schemes and algorithms for power quality improvement and implementation of a flexible control strategy to enhance the performance of UPQC. The enhanced steady state and dynamic performance of UPQC is due to this versatile control strategy using average dc voltage regulation, hysteresis controller based current tracking for shunt active filter and PWM controlled series active filter. The performance of the UPQC is compared with DVR and DSTATCOM. The objectives laid down have been successfully realized through software implementation in MATLAB/SIMULINK. Simulation results show that, when the UPQC applying such control strategy is used for the compensation of the nonlinear/unbalance load conditions in three-phase three-wire system, the harmonic reduction is better; unbalance/distortion of load current and source voltage are compensated well and dc voltage gets regulated all of which verifies the effectiveness of applying such a flexible control strategy in UPQC.

\section{REFERENCES}

[1] C. Sankaran, Power quality, Boca Raton, Fla.: CRC Press LCC, 2002.

[2] Math H.J. Bollen, Understanding power quality problems: Voltage sags and Interruptions, New York: IEEE Press, 2000.

[3] Arindam Ghosh and Gerard Ledwich, Power quality enhancement using custom power devices. Boston: Kluwer Academic Publishers, 2002.

[4] N.G. Hingorani, "Introducing custom power", IEEE Spectrum, vol. 32, no. 6, pp. 41-48, June 1995.

[5] Hirofumi Akagi. "New trends in active filters for power conditioning", IEEE Transactions on Industry Applications, vol. 32, no. 6, pp. 1312-1322, Nov/Dec 1996.

[6] Hirofumi Akagi, "Active harmonic filters", Proceeding of the IEEE, vol. 93, no. 12,pp. 2128-2141, December 2005.

[7] Arindam Ghosh, "Compensation of Distribution System Voltage Using DVR", IEEE Transaction on Power Delivery, vol. 17, no. 4, pp 1030 - 1036, October 2002.

[8] Chris Fitzer, Atputharajah Arulampalam, Mike Barnes, and Rainer Zurowski, "Mitigation of Saturation in Dynamic Voltage Restorer Connection Transformers",IEEE Transactions 